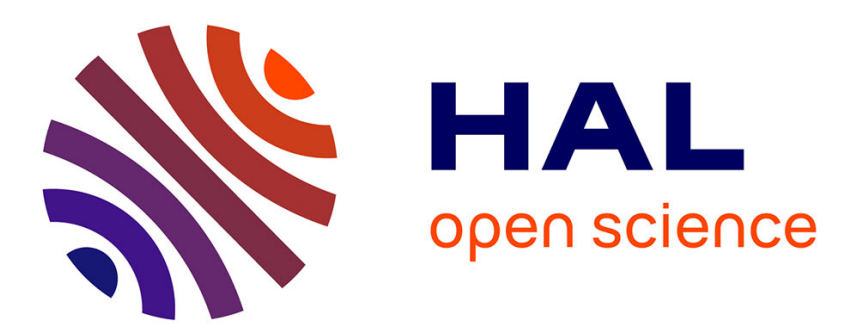

\title{
Fast optical activation of insulator-to-metal transition in vanadium dioxide (VO2) phase changed materials
}

\author{
Aurelian Crunteanu, Jean-Christophe Orlianges, Annie Bessaudou
}

\section{To cite this version:}

Aurelian Crunteanu, Jean-Christophe Orlianges, Annie Bessaudou. Fast optical activation of insulatorto-metal transition in vanadium dioxide (VO2) phase changed materials. Proceedings of SPIE, the International Society for Optical Engineering, 2020, pp.53. 10.1117/12.2544767 . hal-02504112

\section{HAL Id: hal-02504112 \\ https://hal.science/hal-02504112}

Submitted on 13 Nov 2020

HAL is a multi-disciplinary open access archive for the deposit and dissemination of scientific research documents, whether they are published or not. The documents may come from teaching and research institutions in France or abroad, or from public or private research centers.
L'archive ouverte pluridisciplinaire HAL, est destinée au dépôt et à la diffusion de documents scientifiques de niveau recherche, publiés ou non, émanant des établissements d'enseignement et de recherche français ou étrangers, des laboratoires publics ou privés. 


\title{
Fast optical activation of insulator-to-metal transition in vanadium dioxide (VO2) phase changed materials
}

\author{
Aurelian Crunteanu*, Jean-Christophe Orlianges, Annie Bessauadou \\ XLIM Research Institute, CNRS/University of Limoges, 123 avenue Albert Thomas, 87060 \\ Limoges, France
}

\begin{abstract}
Vanadium dioxide $\left(\mathrm{VO}_{2}\right)$ is undergoing a reversible insulator-to-metal transition (MIT), subject to thermal, electrical or optical stimuli. The transition is accompanied by drastic changes in the material's electrical and optical properties which, along the MIT broadband frequency response (from DC to microwaves, THz/ optical domains), triggered a plethora of interesting applications (DC to millimeter-waves switching, $\mathrm{THz}$ modulators, reconfigurable filters and antennas etc.). Here we report on optical switching of the $\mathrm{VO}_{2}$ material between its two dissimilar states when integrated in planar twoterminal electrical devices and submitted to laser pulses with different temporal lengths from a high-power laser diode operating at $980 \mathrm{~nm}$. During optical irradiation of $\mathrm{VO}_{2}$ films with pulses having mean powers between $15 \mathrm{~mW}$ and $140 \mathrm{~mW}$ at repetition rates up to $500 \mathrm{kHz}$, we monitored its resistance change, witnessing on the MIT onset. We demonstrate that the MIT in VO2 is optically triggered for pulses as short as $25 \mathrm{~ns}$ and energies higher than $130 \mathrm{~nJ} / \mathrm{pulse}$, with insulator-to-metal response times in the range 10-15 ns. The process is highly stable and reliable; the devices are able to perform more than one billion switching cycles at frequencies up to $400 \mathrm{kHz}$ without damaging the material nor the device integrity. This optical activation scheme of $\mathrm{VO} 2$ emerges as a promising solution for reconfiguration applications at $\mathrm{THz}$ and millimeter-waves frequencies.
\end{abstract}

Keywords: vanadium dioxide, metal-insulator transition, optical activation, electrical high-frequency switches

\section{INTRODUCTION}

Recent advances in telecommunication systems for civil, defense or space applications, calls for adaptive reconfigurable circuit components at microwave and millimeter-wave frequencies. In order to address the problems related to the increasing number of telecommunication standard multiplication, increasing operating frequencies and overlapping of operating bands, a lot of research have been conducted towards tunable and switchable approaches. Development of smart multifunctional materials with novel properties can be a viable solution for realizing electronic devices with small footprint and faster response time. Strongly correlated oxide materials exhibiting metal-insulator transition (MIT) have been considered as candidates for a large number of applications, including RF switches ${ }^{1,2}$, reconfigurable antennas ${ }^{3,4}$, and filters ${ }^{5,6}$, due to the large contrast in conductivity between the two states along their phase transition. Among them, vanadium dioxide $\left(\mathrm{VO}_{2}\right)$ displays near room temperature phase transition, with an insulating state in the room temperature and a metallic state for temperatures higher than $68^{\circ} \mathrm{C}^{7,8}$. The electrical resistivity of $\mathrm{VO}_{2}$ changes by $3-5$ orders of magnitude between insulating and metal states, which makes it a promising candidate for switching devices, offering easier integration in microelectronic technological processes, faster response time and smaller footprint ${ }^{7,8}$. Insulator to metal transition in $\mathrm{VO}_{2}$ can be triggered by different external stimuli: temperature, optical, electrical-charge injection, and pressure ${ }^{7-11}$. Recent studies showed that electrically- induced MIT in $\mathrm{VO}_{2}$ can have switching times down to several nanoseconds ${ }^{9,10}$. $\mathrm{VO}_{2}$ integration in $\mathrm{RF} /$ microwave devices has been already demonstrated as active, tunable elements using their thermal and electrical activation for phase shifters, filters or power limiters ${ }^{1-6,}$ 12-14 on broad frequency bands and power handling higher than $30 \mathrm{dBm}$, less is reported on the practical integration of an optical activation scheme of MIT in $\mathrm{VO}_{2}$-based RF switches.

In this paper, we report on the electrical properties and optical activation of planar $\mathrm{RF}$ switches integrating $\mathrm{VO}_{2}$ twoterminal devices in single-pole single-throw (SPST) coplanar waveguide (CPW) topology. We are demonstrating that the optical activation scheme of $\mathrm{VO}_{2}$ material may be a fast, reliable switching solution for RF functions showing performances better that the current semi-conductor approaches.

*aurelian.crunteanu@xlim.fr; phone +33 (0) 5875067 41; fax +33 (0) 5554576 49; www.xlim.fr 


\section{EXPERIMENTAL}

$\mathrm{VO}_{2}$ thin films have been obtained on c-cut sapphire substrates by electron beam evaporation of a vanadium target under a reactive oxygen atmosphere ${ }^{15}$. The electrical resistivity variation across the MIT of the obtained films were recorded during heating/cooling cycles (between $25^{\circ}$ and $90^{\circ} \mathrm{C}$ ) by using a current-regulated thermoelectric element (Peltier) and a two- or four-point electrical recording set-up. Figure 1a show the typical temperature-dependent hysteresis of the twopoint square resistance for a $100-\mathrm{nm}$ thick $\mathrm{VO}_{2}$ film obtained on a $20 \mathrm{x} 20 \mathrm{~mm}^{2}$ sapphire substrate. One may observe a drastic change of the film conductivity, by more than four orders of magnitude (conductivity in the insulating state, at $25^{\circ} \mathrm{C}$ of $\sigma_{\mathrm{i}}=2.12 \mathrm{~S} / \mathrm{m}$, and conductivity in the metallic state, at $95^{\circ} \mathrm{C}$ of $\sigma_{\mathrm{m}}=1.23 \times 10^{5} \mathrm{~S} / \mathrm{m}$ ), as the sample temperature pass across the MIT transition temperature around $68^{\circ} \mathrm{C}$.

Further on, in order to evaluate their high-frequency electrical and optical switching performances, $\mathrm{VO}_{2}$ layers were integrated as simple planar two-terminal electrical devices within 50- $\Omega$ coplanar wave guide $(\mathrm{CPW})$ transmission lines topologies, as illustrated in Figure 1b. In this case, the two parts of the discontinued CPW signal line were connected through a $\mathrm{VO}_{2}$ pattern having a width of $60 \mu \mathrm{m}$ and lengths $\mathrm{g}$ with values between 3 and $40 \mu \mathrm{m}$. The devices were realized in a clean room environment using classical micro-fabrication techniques $\left(\mathrm{VO}_{2}\right.$ patterning using photolithography wet etching and metallic electrodes fabrication (Ti/Au $(30 / 300 \mathrm{~nm})$ using optical lithography and ebeam deposition $)^{4,14}$.

The current-voltage (I-V) characteristics of the fabricated switches were recorded using a simple electrical circuit including the $\mathrm{VO}_{2}$ device in series with a resistance $\left(\mathrm{R}_{\mathrm{S}}\right)$ and a source meter (Keithley 2612A). Alternatively, the voltages across the $\mathrm{VO} 2$ switch and of the series resistance were recorded using a large bandwidth oscilloscope (Tektronik DPO7254)
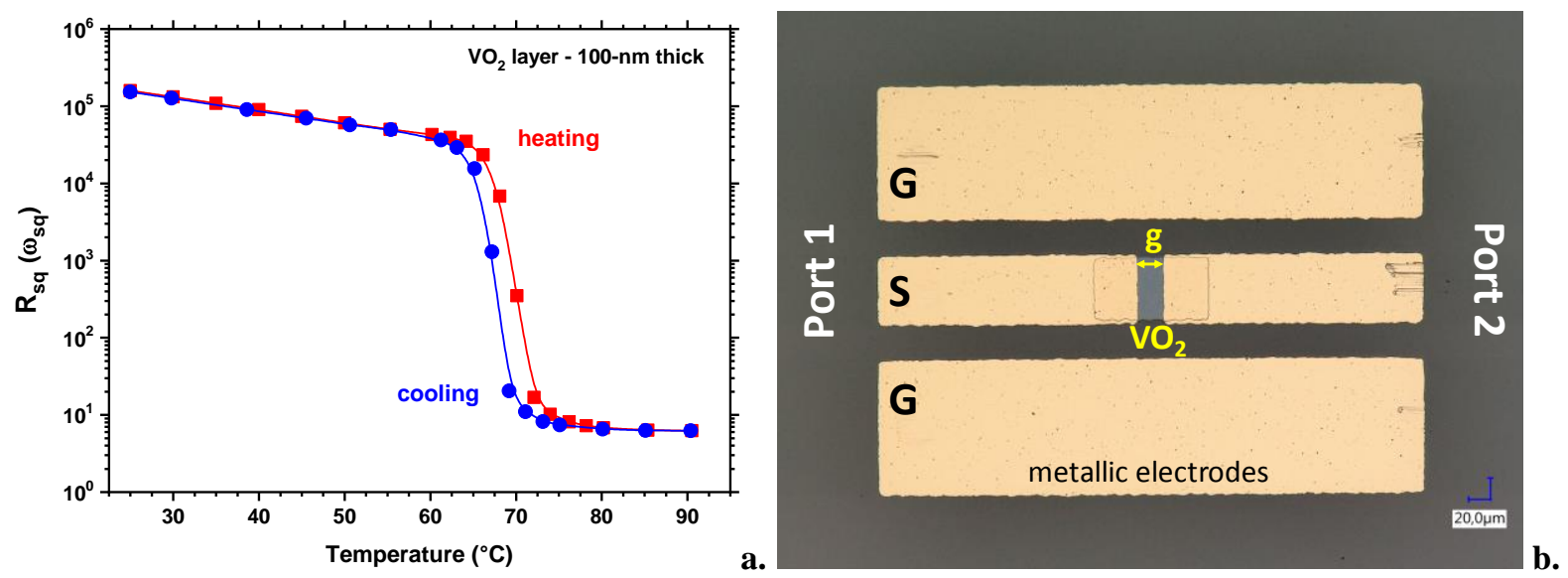

Figure 1. (a) Typical temperature variation of the surface (square) resistance for a $100-\mathrm{nm}$ thick $\mathrm{VO}_{2}$ film obtained on a ccut sapphire substrate and (b) coplanar waveguide (CPW) topology of an $\mathrm{RF}$ switch integrating a $\mathrm{VO}_{2}$ pattern within the signal line $(\mathrm{g}=20 \mu \mathrm{m})$.

\section{RESULTS AND DISCUSSIONS}

\subsection{Electrical and high-frequency performances of the $\mathrm{VO}_{2}$-based devices}

The electrical activation of MIT (E-MIT) was intensively studied in $\mathrm{VO}_{2}$ films ${ }^{1,2,4,9,10}$ since it occurs on fast time-scales (down to few nanoseconds) and offer a higher degree of integration compared to the temperature-induced MIT ${ }^{9}$.

Figure $2 \mathrm{a}$ shows the typical non-linear current-voltage (I-V) characteristics of two SPST devices integrating VO2 patterns with dissimilar lengths g of $10 \mu \mathrm{m}$ and respectively $20 \mu \mathrm{m}$ (gap separating the two parts of the signal line in the $\mathrm{CPW}$ device). As observed, for both type of devices, the increase of the voltage applied in the control circuit induced a clear E-MIT within the $\mathrm{VO}_{2}$, marked by a sudden increase in the current flowing through the device and a decrease of more than four orders of magnitude of the overall resistance of $\mathrm{VO}_{2}$ devices. The specific threshold voltages required for MIT activation are $\mathrm{V}_{\text {th1 }} \approx 13 \mathrm{~V}$ and $\mathrm{V}_{\text {th } 2} \approx 16 \mathrm{~V}$, for devices with $\mathrm{VO}_{2}$ lengths of $\mathrm{g}_{1}=10 \mu \mathrm{m}$ and $\mathrm{g}_{2}=20 \mu \mathrm{m}$, respectively (red, respectively, blue I-V curves on Figure 2a). We may also notice a marked electrical hysteresis of the devices' I-V characteristics, which can be explained by thermal effects associated with Joule heating due to high values of the 
currents flowing through the $\mathrm{VO}_{2}$ after the insulator-to-metal transition. The threshold voltage values can reach values as low as several volts for devices with lengths $\mathrm{g}$ of several microns or below ${ }^{9}$.
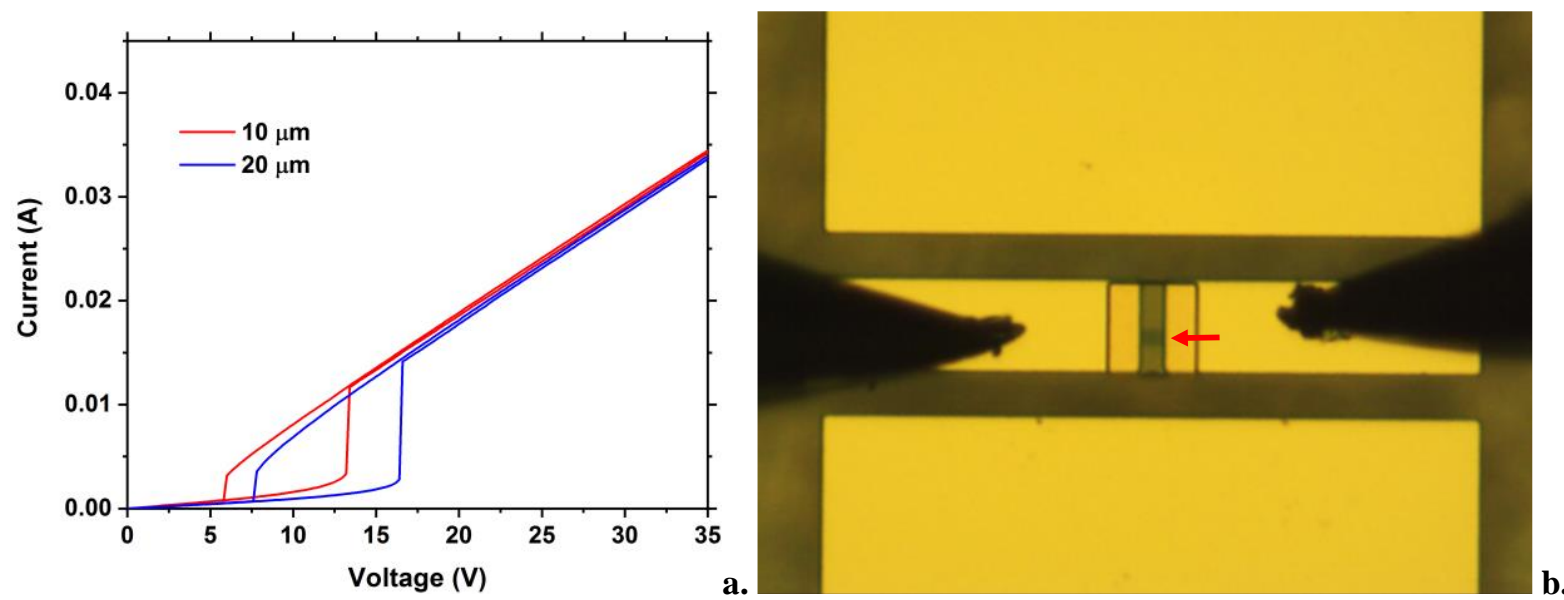

Figure 2. (a) Typical current-voltage (I-V) curves of RF switches integrating 10- and 20- $\mu \mathrm{m}$ length $\mathrm{VO}_{2}$ patterns showing electrical activation of the MIT with dissimilar voltage thresholds and (b) visualization of the metallic $\mathrm{VO}_{2}$ filament appearing within the $\mathrm{VO}_{2}$ pattern for applied voltages higher than the MIT threshold voltage.

The sequential optical images of the $\mathrm{VO}_{2}$ pattern during the voltage-controlled insulator-to-metal transition of the material indicates the appearance of a metallic- $\mathrm{VO}_{2}$ filament ${ }^{17}$. The metallic filament appears at the E-MIT threshold voltage $\left(\mathrm{V}_{\mathrm{th}}\right)$ and its width is increasing with further increase of the applied voltage (to values superior to $\left.\mathrm{V}_{\mathrm{th}}\right)^{17}$. As the applied voltage is lowered, the filaments decreases in width and it disappears for voltage threshold corresponding to the reverse metal-insulator transition in the material.

The broadband RF performances of the fabricated CPW devices were measured in the frequency range from $100 \mathrm{MHz}$ to $40 \mathrm{GHz}$ using a vectorial network analyser (ZVA Rohde\& Schwarz) and ground-signal-ground (GSG) probes. Figure 3 presents the measured $S$ parameters $\left(S_{11}\right.$ - reflection coefficients and $S_{21}$ - transmission parameters) of two SPST switches with $\mathrm{g}_{1}=10 \mu \mathrm{m}$ (red curves) and $\mathrm{g}_{2}=20 \mu \mathrm{m}$ (blue curves), respectively, for both insulating (Figure $3 \mathrm{a}$, at $25^{\circ} \mathrm{C}$ ) and metallic (Figure $3 \mathrm{~b}$, at $95^{\circ} \mathrm{C}$ ) $\mathrm{VO}_{2}$ states. Besides the thermal activation of the MIT in the devices, additional measurements (not shown here) were done by electrically activating the devices, at room temperature. In this case, the $\mathrm{VO}_{2}$ patterns were electrically switched to their metallic state using external dc bias decoupled from the RF signal using bias Ts.
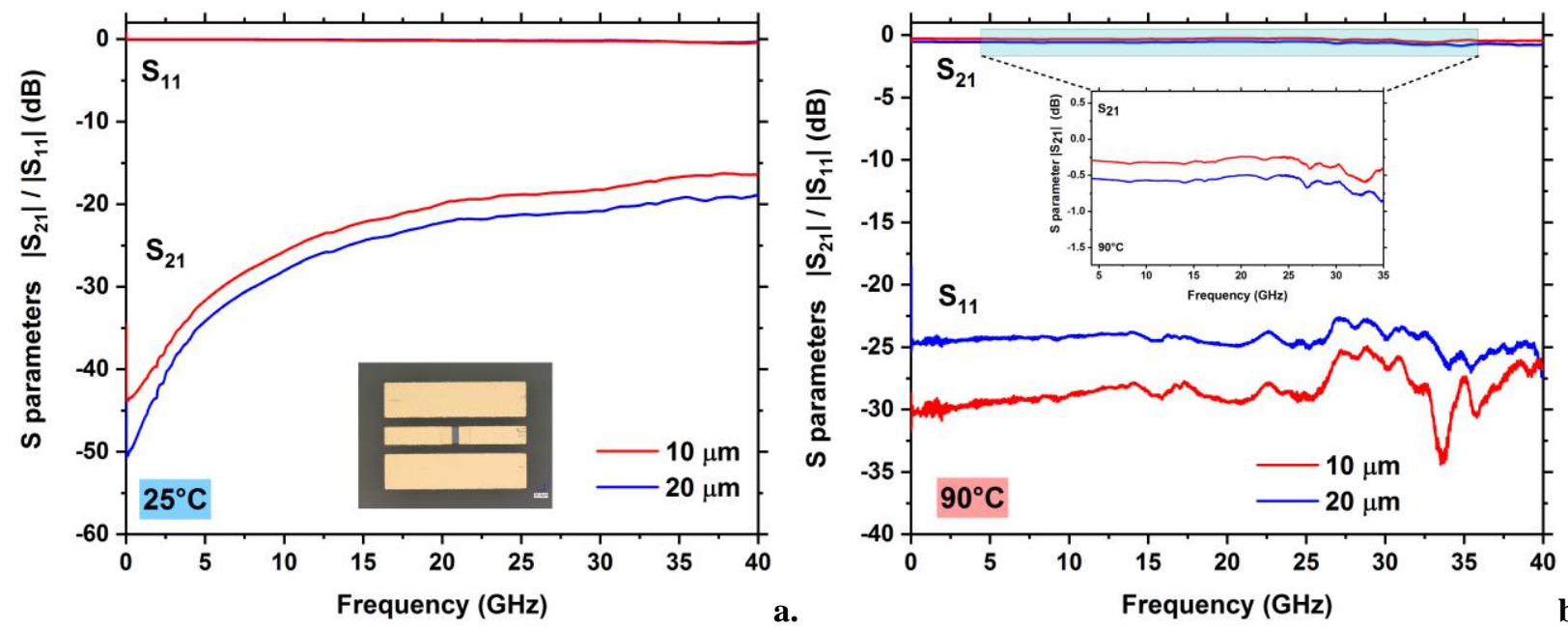

Figure 3. Measured reflection $\left(\mathrm{S}_{11}\right)$ and transmission $\left(\mathrm{S}_{21}\right) \mathrm{S}$ parameters of the RF switches for $\mathrm{VO}_{2}$ patterns with 10- and $20-\mu \mathrm{m}$ lengths at (a) $25^{\circ} \mathrm{C}$ (RF switch in the OFF, blocking state) and (b) at $90^{\circ} \mathrm{C} \mathrm{(RF} \mathrm{switch} \mathrm{in} \mathrm{the} \mathrm{ON}$, transmitting state) 
As observed on the data represented on Figure 3, in the OFF state $\left(\mathrm{VO}_{2}\right.$ insulator at $\left.25^{\circ} \mathrm{C}\right)$, the SPST switch with $\mathrm{g}_{1}=10$ $\mu \mathrm{m}$ (red curves) shows good isolation level, better than $18 \mathrm{~dB}$ in the whole frequency band $(100 \mathrm{MHz}-40 \mathrm{GHz})$, while the isolation is increased to values below $20 \mathrm{~dB}$ for the CPW devices with $\mathrm{g}_{2}=20 \mu \mathrm{m}$ (blue curves). In the $\mathrm{ON}$ state ( $\mathrm{VO}_{2}$ in the metallic state through heating at $95^{\circ} \mathrm{C}$ ), both devices show insertion losses lower than $0.8 \mathrm{~dB}$ in the same frequency range. As expected, the insertion losses for the $\mathrm{CPW}$ device integrating a $\mathrm{VO}_{2}$ pattern with $\mathrm{g}_{1}=10 \mu \mathrm{m}$ are lower, better than $0.5 \mathrm{~dB}$ over the complete measured frequency range.

The measured performances of the RF switches and their modeling using a simple equivalent electrical model (RON, resistance on the $\mathrm{ON}$ state when $\mathrm{VO}_{2}$ is metallic and, $\mathrm{R}_{\mathrm{OFF}}$, resistance on the OFF state in parallel with a capacitance ( $\mathrm{C}_{\mathrm{OFF}}$, capacitance in OFF state) when $\mathrm{VO}_{2}$ is insulator) allow to extract their figure of merit $\left(\mathrm{FOM}=\mathrm{C}_{\mathrm{OFF}} * \mathrm{R}_{\mathrm{ON}}\right.$ expressed in fs) which is describing typical performances of RF switching devices. Typical FOM values of devices with different $\mathrm{VO}_{2}$ lengths $(\mathrm{g}$ ) lie in the range 25-50 fs which are several times better than the FOMs of current semiconductor-based RF commercial switching technologies (between 150 and $300 \mathrm{fs}$ ). The switching times of the electrically induced MIT on the $\mathrm{VO}_{2}-\mathrm{CPW}$ devices (measured using an applied square-type waveform on the CPW switches) shows rising times around $20 \mathrm{~ns}$ (not reported here).

However, it is interesting to note that the performance of the electrical activation of the devices is limited because the MIT in the $\mathrm{VO}_{2}$ pattern is initiated by the appearance of a conductive filament (metallic $\mathrm{VO}_{2}$ surrounded by the insulating parts, as illustrated in Figure 2b) which widens with the rise of the voltage and may not fully cover the width of the $\mathrm{VO}_{2}$ pattern integrated on the $\mathrm{CPW}$ signal line. For voltages higher than the MIT threshold voltage but close to the threshold voltage values, this is resulting in an overall resistance of the $\mathrm{VO}_{2}$ pattern which is not small enough (compared to that obtained by direct heating of the device - when the entire $\mathrm{VO}_{2}$ pattern is switched to its metallic state) and induces higher RF losses than the thermal activation.

From this point of view, in order to circumvent electrical activated MIT with large voltage-current combinations (which will eventually enlarge the metallic filament to the whole $\mathrm{VO}_{2}$ pattern area), optical activation of the $\mathrm{VO}_{2}$ patterns within the CPW devices is a very interesting alternative. This may allow uniform, lower-energy, whole-area activation of MIT within the $\mathrm{VO}_{2}$ patterns and will minimize RF losses in the ON-state of the RF switch.

\subsection{Optical-induced metal-insulator transition in $\mathrm{VO}_{2}$ devices}

In order to evaluate the optical activation of MIT, we directly irradiated the 10- $\mu$ m length $\mathrm{VO}_{2}$ pattern of the CPW device with single laser pulses coming from the end tip of an optical fiber conveying laser pulses from a high-power laser diode operating at an optical wavelength of $980 \mathrm{~nm}$. The laser diode is able to deliver laser pulses with temporal widths between $10 \mathrm{~ns}$ and $30 \mu \mathrm{s}$ and mean powers between $15 \mathrm{~mW}$ and $140 \mathrm{~mW}$ at pulse repetition rates up to $500 \mathrm{kHz}$ (Figure 4a). During optical irradiation of the $\mathrm{VO}_{2}$ pattern, the overall resistance of the device is monitored using a simple electrical circuit in which the $\mathrm{CPW}$ was integrated in series with a dc source (delivering a constant voltage of $2 \mathrm{~V}$ ) and a series resistance of $R_{S}=150 \Omega$. The optical fiber and the electrical probes are positioned on a specific CPW device using piezoelectric manipulators with nanometer-scale resolution (Imina Technologies, Switzerland).
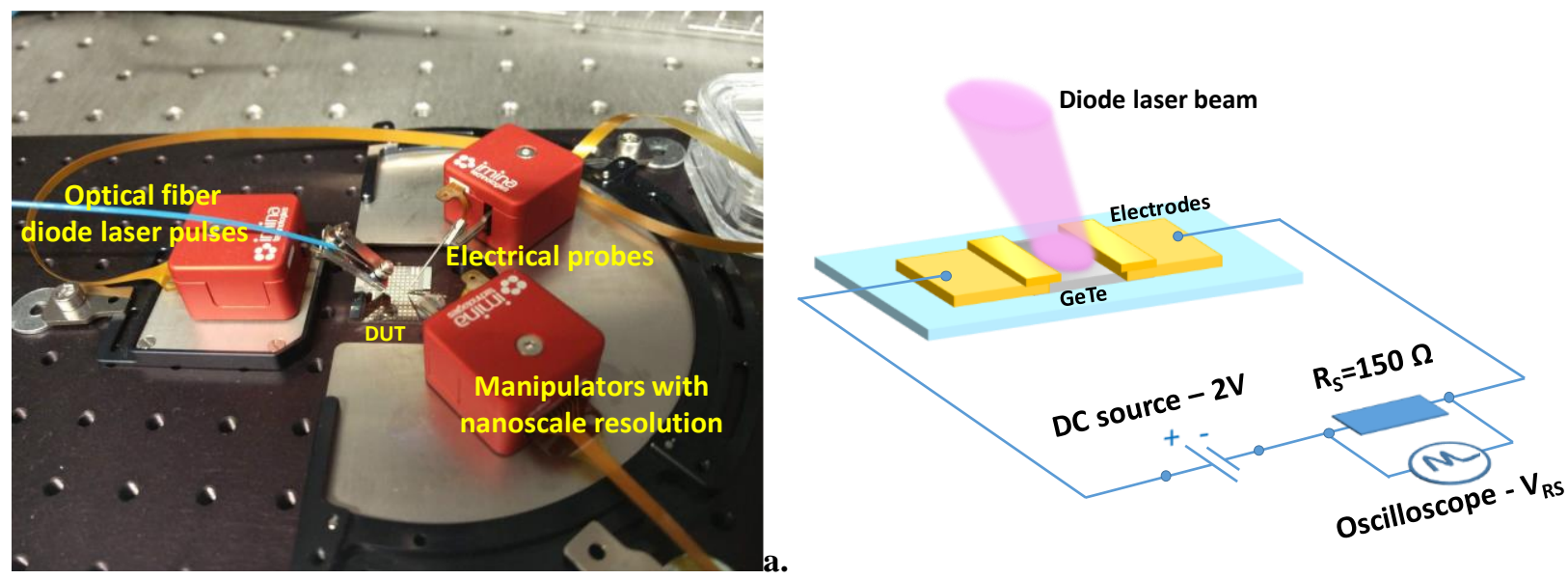

b.

Figure 4. (a) Photography of the implemented set-up and (b) the equivalent electrical circuit used to evaluate the electrical response of the two-terminal $\mathrm{RF}$ switch during optical irradiation of the $\mathrm{VO}_{2}$ pattern. 
The optical irradiation of the $\mathrm{VO}_{2}$ pattern in the CPW device is triggering the MIT for laser pulses as short as $25 \mathrm{~ns}$ and energies between 130 and $170 \mathrm{~nJ} /$ pulse. As indicated on the schematic electrical circuit in Figure 4b, the current modification in the electrical circuit subsequent to the optical-induced MIT (drastic modification of the $\mathrm{VO}_{2}$ pattern resistance and consequently, of the current in the circuit) was recorded on a fast oscilloscope as the voltage variation on the series resistance $\left(\mathrm{V}_{\mathrm{RS}}\right)$ during laser pulsed irradiation of the $\mathrm{VO}_{2}$ pattern. Figure 5a and respectively Figure 5b, are illustrating a closer optical view of the measured device during laser OFF and laser ON continuous-wave operation and the associated voltage drop on the series resistance, respectively.
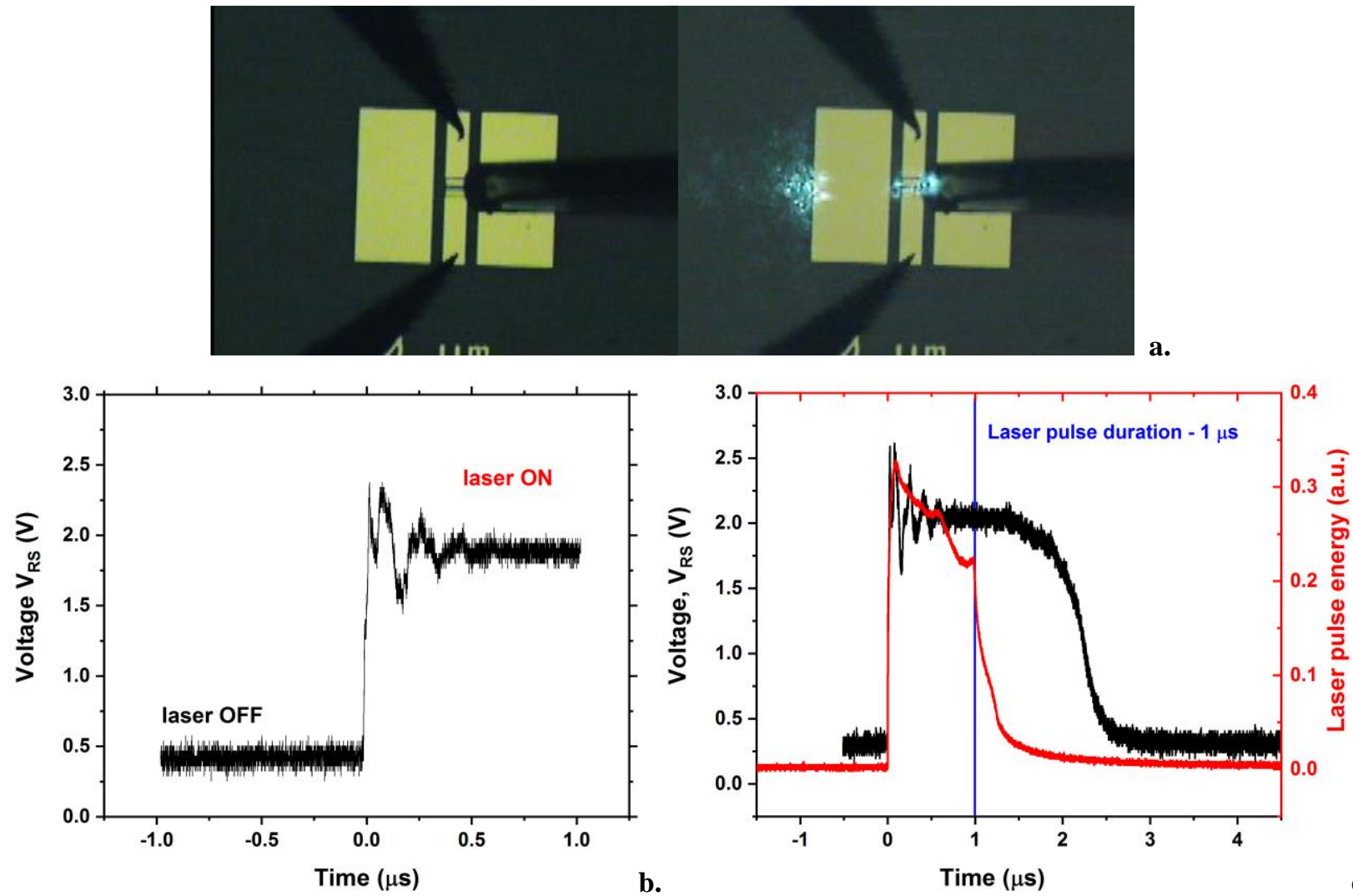

Figure 5. (a) Optical microscopy image of a device under test during laser OFF/ laser ON operation, (b) voltage $\mathrm{V}_{\mathrm{RS}}$ recorded over the series resistance $\mathrm{R}_{\mathrm{S}}$ in Figure 4a during the two extreme ON/ OFF irradiation states (in CW mode) and (c) typical electrical response of the device ( $\mathrm{V}_{\mathrm{RS}}$, black curve) when irradiated with a single laser pulse having a temporal width of 1 us (red curve).

Also plotted on Figure $5 \mathrm{c}$ is the typical electrical response (expressed as the $\mathrm{V}_{\mathrm{RS}}$ voltage variation) of the device subsequent to optical irradiation of the $\mathrm{VO}_{2}$ pattern using a 1- $\mu$ s long single laser pulse (black curve) along with the recorded temporal shape of the delivered laser pulse having an energy of $140 \mathrm{~nJ}$ (red curve).

The recorded electrical response of the CPW device during optical activation of MIT in $\mathrm{VO}_{2}$ allows us to evaluate MIT response times in the range 10-15 ns, depending on the width of the applied laser pulses and their energy. As visible on Figure 5c, the time it takes the device to recover its initial OFF state $\left(\mathrm{VO}_{2}\right.$ back to its insulating state after removing the optical excitation) are much longer than the rise times (typical values between 500 and $1500 \mathrm{~ns}$ ) and restrain the maximum repetition frequencies of the pulsed dynamic ON/OFF operation of the optically-activated switch to around $500 \mathrm{kHz}$. On-going investigations show that the values of the insulating state recovering times depend on the incident optical pulse width, on the RC time constant of the electrical recording circuit (device capacitance and series resistance values dependence) and on the thermal resistance of the overall device.

The reliability of the optical switching of a $10-\mu \mathrm{m}$ long $\mathrm{VO}_{2}$-based $\mathrm{CPW}$ device was evaluated by continuously applying trains of optical pulses of different widths and energies, at repetition frequencies between $100 \mathrm{kHz}$ and $400 \mathrm{kHz}$. Figure 6 shows typical records of the voltage variations on the series resistance upon irradiation of the $\mathrm{VO}_{2}$ pattern using trains 
of 100, 300 and 550 laser pulses (500-ns width) at $200 \mathrm{kHz}$, as well as a detailed view of the pulsed electrical response of the device taken during irradiation with a train of 550 laser pulses. The optical activation of the $\mathrm{VO}_{2}$ is extremely stable and reliable; we were able to perform more than 1 billion switching cycles without damaging the material nor the CPW device.

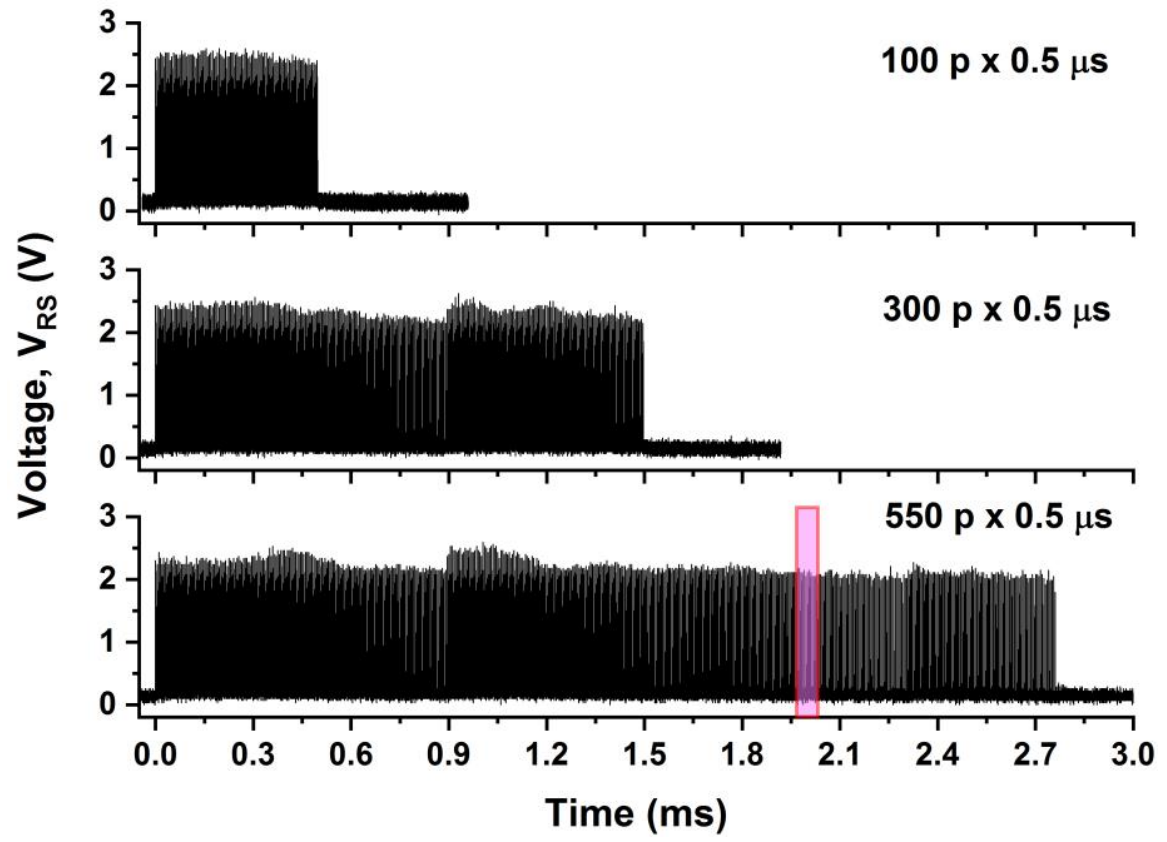

a.

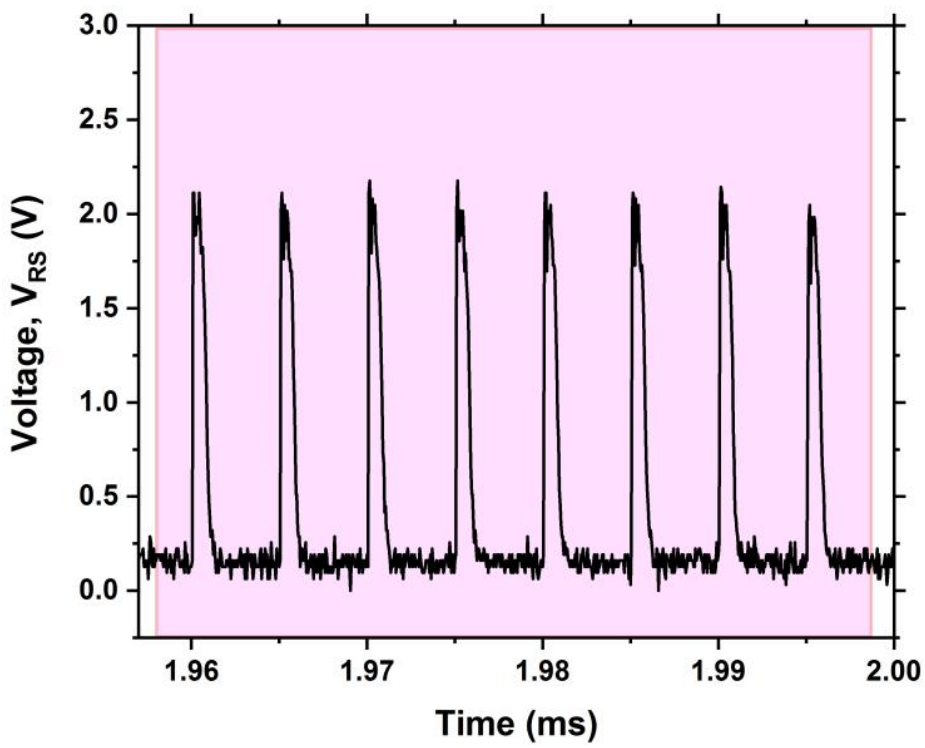

b.

Figure 6. (a) Voltage variation on the series resistance during optical activation of a 10- $\mu \mathrm{m}$ long $\mathrm{VO}_{2}$ pattern within the $\mathrm{RF}$ device using trains of 100, 300 and 550 laser pulses (500-ns width, $200 \mathrm{kHz}$ ) and (b) zoom-in of the electrical response corresponding to the pink-colored area in figure (a).

\section{CONCLUSIONS}

We presented the design, fabrication, and high frequency characterization of RF switches based on $\mathrm{VO}_{2}$ integration in $\mathrm{CPW}$ lines with very good RF performances on a broad frequency band. The $\mathrm{VO}_{2}$-based devices were actuated between their $\mathrm{ON}$ and OFF state on nanosecond timescales, using both electrical and optical short laser pulses. The investigation 
of their RF properties show that the devices present high OFF-state isolation, high resistivity ratio $\left(\mathrm{R}_{\mathrm{OFF}} / \mathrm{R}_{\mathrm{ON}}\right)$, low insertion losses, and very good figures of merit. The optical activation scheme of $\mathrm{VO}_{2}$ we are proposing here may be relevant for applications in which the RF interference commonly associated with extensive electrical control circuitry of RF devices (e.g. antennas and antenna networks) must be avoid and is emerging as a promising solution for reconfiguration and agility applications in the millimeter-waves to $\mathrm{THz}$ frequencies range.

\section{REFERENCES}

[1] S. D. Ha, Y. Zhou, C. J. Fisher, S. Ramanathan, and J. P. Treadway, "Electrical switching dynamics and broadband microwave characteristics of VO2 radio frequency devices," J. Appl. Phys., 113, 184501 (2013).

[2] W. A. Vitale, A. Paone, M. Fernández-Bolaños, A. Bazigos, W. Grabinski, A. Schüler, Adrian M. Ionescu, "Steep slope VO2switches for wide-band (DC-40 GHz) reconfigurable electronics," in 72nd Device Research Conference, 29-30 (2014).

[3] T. S. Teeslink, D. Torres, J. L. Ebel, N. Sepulveda, and D. E. Anagnostou, "Reconfigurable Bowtie Antenna Using Metal-Insulator Transition in Vanadium Dioxide," IEEE Ant. Wirel. Propag. Lett., 14, 1381-1384 (2015).

[4] L. Huitema, A. Crunteanu, H. Wong, and E. Arnaud, "Highly integrated VO 2 -based tunable antenna for millimeter-wave applications,” Appl. Phys. Lett., vol. 110, no. 20, p. 203501 (2017).

[5] D. Bouyge et al., "Applications of vanadium dioxide (VO2)-loaded electrically small resonators in the design of tunable filters," in The 40th European Microwave Conference, 822-825 (2010).

[6] W. A. Vitale, L. Petit, Clara, F. Moldovan, M. Fernández-Bolaños, A. Paone, A. Schüler, Adrian M.Ionescu, "Electrothermal actuation of vanadium dioxide for tunable capacitors and microwave filters with integrated microheaters," Sens. Actuators Phys., 241, 245-253 ( 2016).

[7] Z. Yang, C. Ko, and S. Ramanathan, "Oxide Electronics Utilizing Ultrafast Metal-Insulator Transitions," Annu. Rev. Mater. Res., 41, 337-367 (2011).

[8] F. J. Morin, "Oxides Which Show a Metal-to-Insulator Transition at the Neel Temperature,” Phys. Rev. Lett., 3(1), 34-36 (1959).

[9] J. Leroy, A. Crunteanu, A. Bessaudou, F. Cosset, C. Champeaux, and J.-C. Orlianges, "High-speed metalinsulator transition in vanadium dioxide films induced by an electrical pulsed voltage over nano-gap electrodes," Appl. Phys. Lett., 100 (21), 213507 (2012).

[10] G Stefanovich, A Pergament and D Stefanovich, "Electrical switching and Mott transition in VO 2," J. Phys. Condens. Matter, 12 (41), 8837 (2000).

[11] A. Cavalleri Cs. Tóth, C. W. Siders, J. A. Squier, F. Ráksi, P. Forget, and J. C. Kieffer, "Femtosecond Structural Dynamics in VO2 during an Ultrafast Solid-Solid Phase Transition,” Phys. Rev. Lett., 87, 237401 (2001).

[12] C. Hillman, P. A. Stupar, J. B. Hacker, Z. Griffith, M. Field, and M. Rodwell, "An ultra-low loss millimeterwave solid state switch technology based on the metal - insulator - transition of vanadium dioxide," in IEEE MTT-S International Microwave Symposium, 1-4 (2014).

[13]A. Crunteanu, G. Humbert, J. Leroy, L. Huitema, J.-C. Orlianges, and A. Bessaudou, "Tunable THz metamaterials based on phase-changed materials (VO2) triggered by thermal and electrical stimuli," Proc. SPIE, San Francisco, CA, United States, 101031H (2017).

[14] A. Mennai A. Bessaudou, F. Cosset, C. Guines, D. Passerieux, P. Blondy, A. Crunteanu, "High cut-off frequency RF switches integrating a metal-insulator transition material," IEEE MTT-S International Microwave Symposium, 1-3 (2015).

[15] J. Leroy, A. Bessaudou, F. Cosset, A. Crunteanu, "Structural, electrical and optical properties of thermochromic VO2 thin films obtained by reactive electron beam evaporation", Thin Solid Films 520, 4823-4825, (2012).

[16] A. Crunteanu, J. Givernaud, J. Leroy, David Mardivirin, C. Champeaux, J.-C. Orlianges, A. Catherinot and P. Blondy, "Voltage- and current-activated metal-insulator transition in VO2-based electrical switches: a lifetime operation analysis", Sci. Technol. Adv. Mater. 11, 065002 (2010).

[17] A. Crunteanu, M. Fabert, J. Cornette, M. Colas, J.-C. Orlianges, A. Bessaudou, F. Cosset, "Electric fieldassisted metal insulator transition in vanadium dioxide (VO2) thin films: optical switching behavior and anomalous far-infrared emissivity variation", Proc. SPIE 9364, pp.93640J1-J11 (2015). 